\title{
Management of huge and extraordinary metal-penetrating injuries to the hand
}

Osman Akdağ, Gökçe Yıldıran, Mehtap Karameșe

\begin{tabular}{|c|c|}
\hline \multirow[t]{5}{*}{ ABSTRACT } & $\begin{array}{l}\text { Objective: Foreign-body and penetration injuries of the hand are common emergencies. Metallic foreign bodies are } \\
\text { common among all foreign masses; however, the examination of huge bodies differs from that of other metallic } \\
\text { masses. The purpose of this study was to clarify an algorithm for the management of the huge metallic masses via } \\
\text { our therapeutic approaches for metal-penetrating injuries. }\end{array}$ \\
\hline & $\begin{array}{l}\text { Material and Methods: Seven patients who had a huge, metallic object-penetration injury to their upper extremity } \\
\text { were included in our study. Patients were classified according to the age, injury type, character of metallic body, } \\
\text { injury zone, diagnostic methods, anesthesia type, and treatment received, and an algorithm to approach the mana- } \\
\text { gement of foreign metallic bodies was clarified. }\end{array}$ \\
\hline & $\begin{array}{l}\text { Results: The causes of injury were knitting hook, iron fence, mixer, and metal nail. Plain radiography was performed } \\
\text { for all patients. Prophylactic tetanus was administered and urgent exploration in the operation room under tourni- } \\
\text { quet followed by foreign-body extraction through cutting and not pulling were conducted. No residue was retained. }\end{array}$ \\
\hline & $\begin{array}{l}\text { Conclusion: Many patients referred to emergency services with foreign bodies. For diagnosis, the patient's history } \\
\text { and a minimum of two-way radiograms are crucial. For treatment, we recommend surgical exploration under gene- } \\
\text { ral anesthesia and tourniquet and extraction of the metallic body by cutting and not pulling without retaining any } \\
\text { residual mass in the operation room. }\end{array}$ \\
\hline & Keywords: Foreign body, hand, mass, metal \\
\hline
\end{tabular}

Cite this paper as: Akdağ 0 , Yıldıran G, Karameşe M. Management of huge and extraordinary metal-penetrating injuries to the hand. Turk J Surg 2018; 34: 117-120.

Department of Plastic Reconstructive and Aesthetic Surgery, Selçuk University School of Medicine, Konya, Turkey

This study was presented at the "1 $14^{\text {th }}$ National Congress of the Turkish Society for Surgery", Bursa, Turkey.

\section{Corresponding Author Gökçe Yıldıran}

e-mail: ggokceunal@gmail.com

Received: 09.04.2017

Accepted: 26.05 .2018

CCopyright 2018 by Turkish Surgical Association Available online at www.turkjsurg.com

\section{INTRODUCTION}

Foreign bodies and penetration injuries of the hand are common emergencies. These cases are crucial because of the possibility of neurovascular, skeletal, or soft tissue injuries; allergic reactions; migration; or delayed wound healing (1).

Metallic foreign bodies are common among all foreign masses; however, the examination of the huge bodies differs from that of other metallic masses. Also, huge metallic bodies may present as traumatic and reactive masses and can be a mechanical load for the hand or can cause hand disabilities. In addition, huge metallic bodies are challenging to remove due to a high risk associated with pulling the mass.

The purpose of this study was to clarify an approach for the management of the huge metallic masses via our therapeutic approaches for metal-penetrating injuries.

\section{MATERIAL AND METHODS}

Seven patients who had an extraordinary, metallic object-penetration injury between January 2012 and January 2015 were included in the study. All patients were admitted within 24 hours. The study was designed in accordance with the principles of Helsinki Declaration.

Metallic splinters and bullet penetration cases were excluded because these were not classified as huge objects. The criterion for an extraordinary object was being a visible penetrating mass. Patients admitted with residual foreign bodies, high-pressure injection injuries, and foreign bodies other than metal (such as wooden splints, glass, and mercury) injury were excluded from the study. If patients did not already have a foreign body in their hand, they were excluded from the study even if they were injured with a metal foreign body (such as needle stick or fishhook injuries).

Patients were retrospectively classified according to the age $(<18,18-65$, or $>65$ years), injury type (industrial injury, home accident, or others), nature of the metallic body (knitting hook, iron fence, metal nail, mixer, or others), injury zone (finger, palm, or wrist), diagnostic methods (hand examination, X-ray, ultrasonography, magnetic resonance imaging, none, or combined), anesthesia type (local, regional, or general), treatment received (medical or surgical), and hand sequelae. All masses were evaluated according to their shape. If the body had a protruding end, this end was first cut to prevent additional 


\section{Table 1. Treatment algorithm}
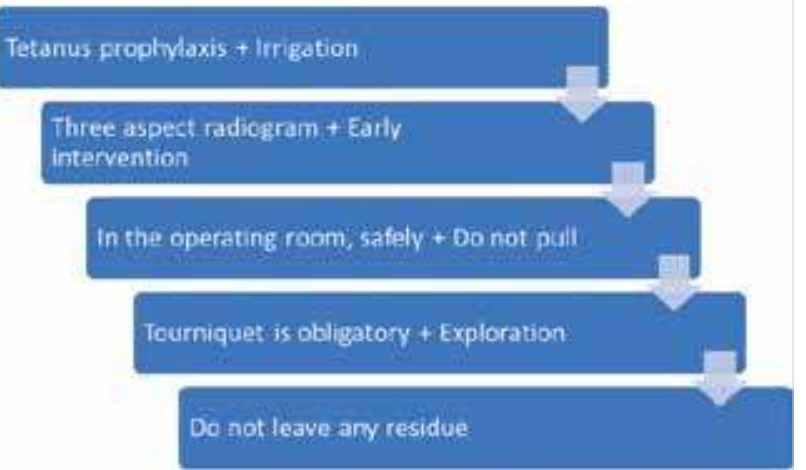

injuries while pulling out the body. Thereafter, the end of the metallic mass and the main body were pulled one by one. An approach to manage the foreign metallic bodies penetration was thus clarified (Table 1).

\section{RESULTS}

Four females and three males with an age range of 14-51 (mean, 33.5) years were evaluated. Five of seven (71.4\%) injuries were home accidents. The causes of injury were knitting hook in three patients, iron fence in two patients, mixer in one patient, and metal nail in one patient. Furthermore, fingers in two, palms in two, wrists in three patients were the affected regions (Figure 1, 2).
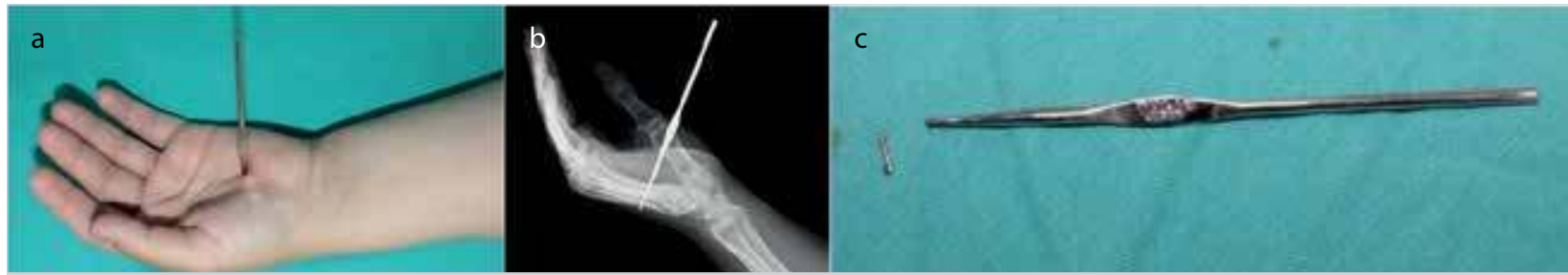

Figure 1. a-c. A 23-year-old female patient was admitted with a knitting hook penetrated in her palm (a). There were no neurovascular or skeletal injuries; radiogram (b); the hook was removed not by pulling but by cutting its head (c). No residue was retained

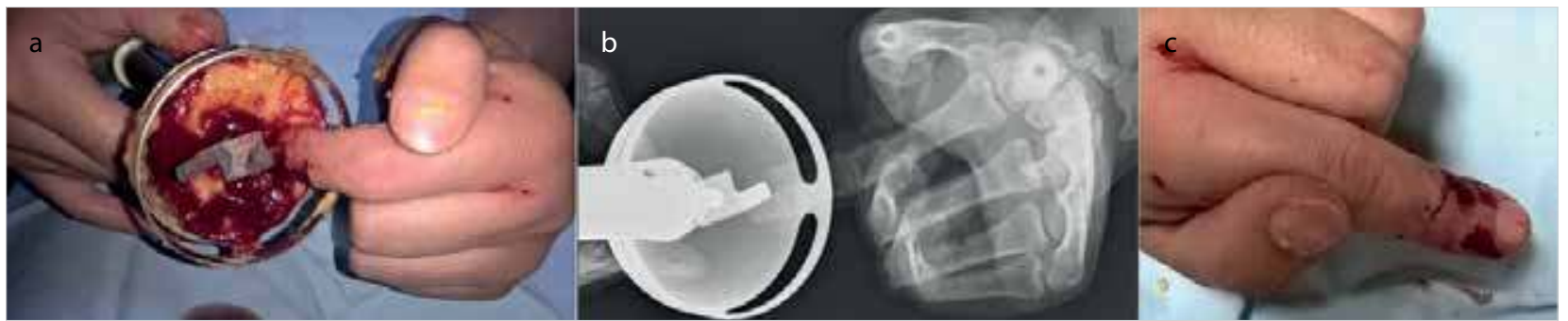

Figure 2. a-c. A 46-year-old female patient was admitted with kitchen mixer penetration in her left hand index finger (a); radiogram (b); the mixer was removed and patient was

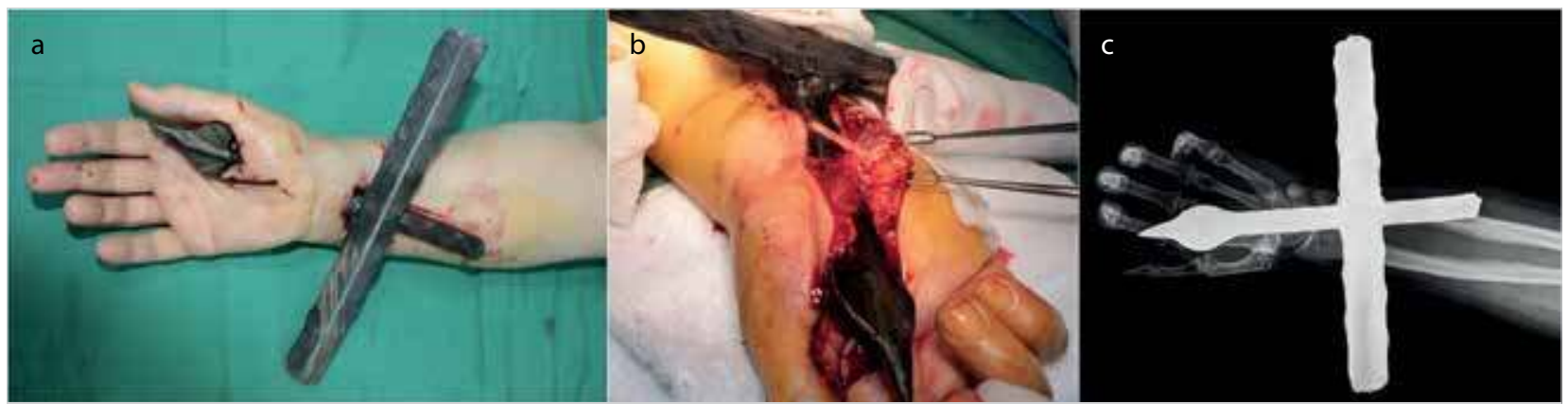

Figure 3. a-c. A 51-year-old female patient was admitted with iron fence penetrated from her wrist to the thenar region of the hand via the carpal tunnel (a); the fence did not cause any neurovascular or tendon injury (b); radiogram (there were no skeletal injuries) (c). Fence was removed completely without any residue

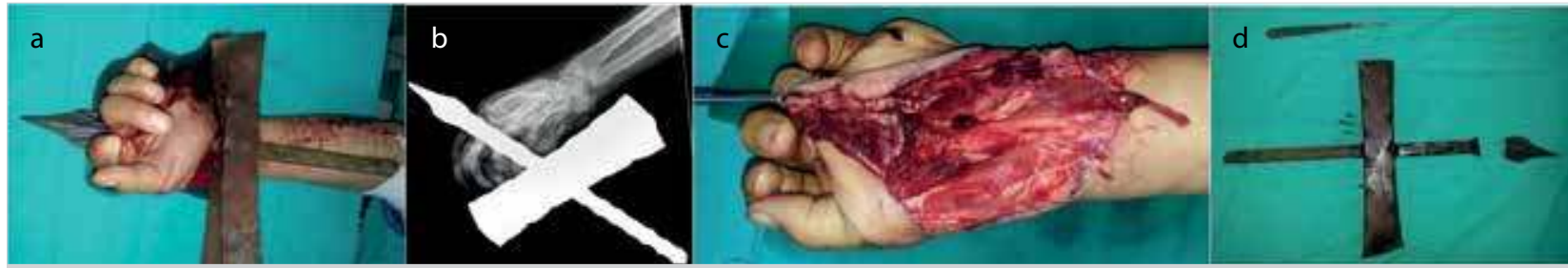

Figure 4. a-d. A 14-year-old male patient was admitted with iron fence penetrated from his thenar region to the second web of the hand (a); radiogram (b); he had flexor pollicis longus, second flexor digitorum longus tendons, and ulnar artery injury. Injured structures were repaired (c); the fence was removed not by pulling but cutting its head without any residue (d). He received rehabilitation for the hand in the early recovery period 
Patients' history was obtained, and a detailed hand examination was performed for all patients. In some patients, in whom the penetrating mass was deep and sharp, tendon examination was not performed aggressively (Figure 3,4).

For all patients, tetanus prophylaxis was administered in the emergency room. Extremities were covered with simple dressing until the patients were shifted to the operating room. Plain radiography was performed for the patients from three aspects, and photographs were captured. All wounds were irrigated. The respective foreign bodies were removed in the operation room on an urgent basis. Three injuries were required to be removed under general anesthesia; four were removed under local anesthesia. For all patients, a pneumatic tourniquet was used. During surgery, all the hand functions were preserved, and patients underwent hand physiotherapy postoperatively. The masses were removed by cutting, and no residue material was left behind. Postoperative radiograms and photographs were captured.

\section{DISCUSSION}

Many patients present to emergency services with foreignbody injuries. The most common foreign bodies are wooden splints, metallic fragments, and glass and stone pieces (2). Metallic foreign bodies constitute a majority of the foreign bodies. However, some types of metal foreign bodies that may result much more serious situations are more than only a mass, forming a mechanical load for the hand.

The body's response to foreign mass differs according to the anatomical region, content of the foreign body, time elapsed since penetration of the mass, and if there is tissue hypersensitivity for the foreign body. Foreign bodies that include iron cause less hypersensitivity reactions than those containing aluminum, copper, or mercury $(3,4)$. Most of our patients injured by iron; however, we examined the injury in the early period and noted no hypersensitivity.

The injury types presented in this study are related to visible foreign bodies. Hence, other clinical scenarios of a differential diagnosis may be negligible. For diagnosis, a minimum of twoway radiograms are crucial $(5,6)$. However, it should be considered that wood, plastic, glass without silisium, and aluminum are radiolucent (7). In metallic-body injuries, not only skeletal injuries are seen but also the localization and shape of the metallic objects are visualized; thus, radiograms are crucial. For interpreting the exact localization of the foreign body, scopies and markings with needles or wires are useful. Today, imaging systems are advantageous in capturing the images. We obtained three-way radiograms for all our patients to evaluate skeletal injuries, which may occur due to an extraordinary metallic object (Figure 2-4), and to evaluate the exact localization (Figure 1).

We recommend radiograms for masses even if they may be diagnosed by inspection to evaluate for an additional mass, a fractured metallic mass, or a skeletal injury. Besides, radiograms are crucial to evaluate the shape of the penetrated body. If the metallic object has a hook or ends as an arrow, this side should firstly be cut and separated from the main body. If there is a hook or arrow, the metallic object should not be removed by pulling or rotating the main mass because of the high risk of additional injuries. Also, photographs should be taken perioperatively for medicolegal issues in these cases. Because all the masses were visible and metallic, we utilized from 3-aspect-radiograms. However, if residual foreign-body suspicion persists, ultrasonography or computed tomography may be performed (5-8).

After recognizing the metallic body, the patient should be administered tetanus treatment as prophylaxis, and wound irrigation and urgent surgical interventions should be performed (9). We performed urgent surgical intervention in the operating room. Operating rooms are better than emergency rooms in terms of sterility, and both intraoperative and postoperative analgesia can be more easily provided in the operating rooms. We also observed that patients for psychological stability in the operating room. Loco-regional or general anesthesia can be applied. Often, even if regional anesthesia is administered, sedation should be included in the anesthesia for agitated or irritated patients. In the operating room, the metallic object should be removed safely not by pulling or rotating but by cutting. We removed all the foreign bodies by cutting and separating the two ends of the metallic objects from each other. Sometimes, it is necessary to make an extra, small incision for adequate exposure. We made an additional incision in one patient (Figure 3). During this procedure, no residual mass should be left behind. While exploring the hand, all the masses were removed. However, we recommend intraoperative fluoroscopy if there is a doubt of persistent or residual foreign body.

\section{CONCLUSION}

It is obligatory to obey the basic rules of removing foreign bodies, such as tetanus prophylaxis and irrigation, in the emergency room. However, for huge and penetrating objects, some additional processes, such as removing the body in the operating room by cutting and without pulling, rotating, or any residual mass, exploration of the hand, and physiotherapy, should be considered while developing the algorithm of removing metallic foreign bodies.

Ethics Committee Approval: Authors declared that the research was conducted according to the principles of the World Medical Association Declaration of Helsinki "Ethical Principles for Medical Research Involving Human Subjects".

Informed Consent: Written informed consents were obtained from patient who participated in this study.

Peer-review: Externally peer-reviewed.

Author Contributions: Concept - G.Y., O.A.; Design - G.Y., O.A.; Supervision - O.A., M.K.; Resource - O.A., G.Y., M.K.; Materials - G.Y.; Data Collection and/or Processing - G.Y., O.A.; Analysis and/or Interpretation - G.Y., O.A.; Literature Search - O.A., G.Y.; Writing Manuscript - G.Y., O.A.; Critical Reviews - O.A., M.K.

Conflict of Interest: The authors have no conflicts of interest to declare.

Financial Disclosure: The authors declared that this study has received no financial support. 


\section{REFERENCES}

1. Hocaoğlu E, Kuvat SV, Özalp B, Akhmedov A, Doğan Y, Kozanoğlu $E$ et al. Foreign body penetrations of hand and wrist: a retrospective study. Ulus Travma Acil Cerrahi Derg 2013; 19: 58-64. [CrossRef]

2. Salati SA, Rather A. Missed foreign bodies in the hand: an experience from a center in Kashmir. Libyan J Med 2010; 5: DOI: 10.3402/ljm.v5i0.5083. [CrossRef]

3. Hostynek JJ, Maibach HI. Copper hypersensitivity: dermatologic aspects. Dermatol Ther 2004; 17: 328-333. [CrossRef]

4. George A, Kwatra KS, Chandra S. Cutaneous mercury granuloma following accidental occupational exposure. Indian J Dermatol Venereol Leprol 2015; 81: 57-59. [CrossRef]
5. Anderson MA, Newmeyer WL 3rd, Kilgore ES Jr. Diagnosis and treatment of retained foreign bodies in the hand. Am J Surg 1982; 144: 63-67. [CrossRef]

6. Hung YT, Hung LK, Griffith JF, Wong CH, Ho PC. Ultrasound for the detection of vegetative foreign body in hand--a case report. Hand Surg 2004; 9: 83-87. [CrossRef]

7. Kaiser CW, Slowick T, Spurling KP, Friedman S. Retained foreign bodies. J Trauma 1997; 43: 107-111. [CrossRef]

8. Mason ML, Wheelock MC. Penetration of metallic mercury into the soft tissues of the hand. Q Bull Northwest Univ Med Sch 1959; 33: 1-5.

9. Keskin M, Beydes T, Tosun Z, Savaci N. Close range gun shot injuries of the hand with the "mole gun". JTrauma 2009; 67: 139-142.[CrossRef] 